\title{
Crescimento e acúmulo de matéria seca em variedades de cana-de-açúcar cultivadas sob irrigação plena
}

\author{
Emídio C. A. de O liveira ${ }^{1}$, Ruthanna I. de 0 liveira ${ }^{2}$, Bruna M. T. de Andrade ${ }^{2}$, \\ Fernando J. Freire'2, Mario A. Lira Júnior ${ }^{2} \&$ Paulo R. Machado $^{3}$
}

\begin{abstract}
RESU MO
A análise de crescimento é considerada o método padrão para medir a produtividade biológica em espécies vegetais. Neste contexto objetivou-se avaliar, em onze variedades de cana-de-açúcar (SP79-1011, RB813804, RB863129, RB872552, RB943365, RB72454, RB763710, SP78-4764, SP81-3250, RB867515, RB92579) cultivadas sob irrigação plena, o crescimento e a produção de matéria seca no ciclo de cana planta. 0 experimento foi instalado em condições de campo no município de Carpina, PE. U tilizou-se o delineamento estatístico de blocos ao acaso, com quatro repetições. A anál ise de crescimento correspondeu à quantificação dos números de perfilhos e à, na mensuração da altura e diâmetro dos colmos, avaliados mensalmente em onze períodos de cultivo, os quais se estenderam dos 60 aos 360 dias após o plantio (DAP). A produção de matéria seca foi quantificada a partir dos 120 DAP, com intervalos de amostragem a cada dois meses. 0 bservou-se que as variedades RB92579 e SP81-3250 apresentaram o maior perfil hamento e produção de matéria seca e as variedades RB813804 e RB72454 às maiores médias de altura, enquanto as variedades RB867515 e RB72454 obtiveram os maiores diâmetros do colmo.
\end{abstract}

Palavras-chave: Saccharum spp, perfilhamento, altura, diâmetro, produção biológica

\section{Growth and dry matter production in sugarcane varieties grown under full irrigation}

\begin{abstract}
Growth analysis is considered as a standard method for measuring the biological productivity of plant species. The objective of this research was to evaluate the growth and dry matter production of el even sugarcane varieties (SP79-1011, RB813804, RB863129, RB872552, RB943365, RB72454, RB763710, SP78-4764, SP81-3250, RB867515, RB92579), grown under full irrigation, in the planted cane cycle. The experiment was conducted in field conditions in the municipality of Carpina, PE. A randomized block design with four replications was used. The varieties' growth analysis was represented by the quantification of the tillers numbers, stalk height and diameter, measured monthly, in el even periods of cultivation that extended from 60 to 360 days after planting (DAP). The dry matter production was measured from 120 DAP, with sampling intervals of every two months. It was observed that, at 360 DAP, the RB92579 and SP81-3250 varieties showed the highest tillering and dry matter production. The RB813804 and RB72454 varieties had the highest average for height, while the RB72454 and RB867515 varieties presented the largest stalk diameters.
\end{abstract}

Key words: Saccharum spp, tillering, height, diameter, biological production

\footnotetext{
${ }^{1}$ ESALQ/USP, Av. Centenário CP 96, CEP 13400-970, Piracicaba, SP. Fone: (19) 3429-4738. E-mail: ecaoliveira@cena.usp.br 2 Centro de Pesquisa de Solos/UFRPE. Rua Dom Manuel de Medeiros, Campus Universitário de Dois Irmãos, CEP 52171-900, Recife, PE. Fone: (81) $3320-6220$. E-mail: rhuty_isa@hotmail.com; bruannamarcela@hotmail.com; f.freire@depa.ufrpe.br; mario.lira@depa.ufrpe.br

EECAC/U FRPE, Rua Ângela Cristina Pessoa de Luna, s/n, CEP 55810-700, Carpina, PE. Fone: (81) 3622-0444. E-mail: machadop_rocha@yahoo.com.br
} 


\section{INTRODUÇÃO}

Nas regiões canavieiras do Brasil, como a Zona da Mata do Nordeste, a disponibilidade de área para expansão da canade-açúcar vem-se tornando cada vez mais escassa, sendo imprescindível manejar a cultura adequadamente, em busca de maiores produções por unidade de área. Contudo, a má distribuição e as baixas quantidades pluviométricas comumente observadas nessas regiões produtoras, restringem o crescimento da cultura e proporcionam impactos negativos da produtividade e qualidade dos canaviais (Wiedenfeld \& Enciso, 2008). Nessas condições, o manejo adequado implica na identificação dos padrões de crescimento, permitindo selecionar variedades edafoclimaticamente adaptadas aos diferentes ambientes de produção e que se revelem eficientes no uso da água, principalmente em sistemas de cultivos irrigados.

A análise de crescimento da cana-de-açúcar tem permitido identificar as fases de desenvolvimento da cultura nos diferentes ambientes de cultivo, proporcionando sua condução, de forma que o máximo desenvolvimento coincida com os períodos de maior disponibilidade hídrica e radiação solar, o que leva a cultura a expressar todo o seu potencial genético, além de permitir manejar diferentes formas de adubação e tratos culturais (Stone et al., 1999). O crescimento da parte aérea da cana-de-açúcar pode ser dividido em três etapas: fase inicial, em que o crescimento é lento; fase de crescimento rápido, com surgimento e alongamento de entrenós, em que se acumulam cerca de $75 \%$ da matéria seca total, e fase final, em que novamente há crescimento lento (Robertson et al., 1996; Inman-Bamber et al., 2002; Oliveira et al., 2007).

A avaliação de algumas variáveis morfológicas das plantas, como altura, diâmetro, plantas $\mathrm{m}^{-1}$, área foliar e produção, torna possível a identificação da capacidade produtiva de diferentes variedades e a investigação dos efeitos do manejo da cultura. Adicionalmente, a análise de crescimento pode ser realizada por meio de avaliações sequenciais do acúmulo de matéria seca e/ou fresca ou, ainda, dos índices fisiológicos dela obtidos (Gava et al., 2001). Assim, a identificação das prováveis variações no desenvolvimento da cana-de-açúcar que ocorrem durante o ciclo, é fundamental para que se possa modelar e quantificar o crescimento nos diferentes ambientes de produção (Teruel et al., 1997).

Diante do exposto, a presente pesquisa teve como objetivo avaliar o crescimento e a produção de matéria seca dos componentes da parte aérea de onze variedades de cana-deaçúcar cultivada em Argissolo Amarelo distrófico e submetidas a regime de irrigação plena durante o ciclo de cana planta.

\section{MATERIAL E MÉTODOS}

O estudo foi realizado na Estação Experimental de Canade-açúcar de Carpina (EECAC), Unidade de Pesquisa da Universidade Federal Rural de Pernambuco (UFRPE), localizada no município de Carpina, Zona da Mata Norte do Estado, durante o ciclo de cana planta, na safra agrícola 2006/2007. Constataram-se durante o desenvolvimento da pesquisa precipitação pluvial anual de $1.181 \mathrm{~mm}$ e temperaturas médias superiores a $25^{\circ} \mathrm{C}$ (Figura 1 ).

O solo da área experimental foi classificado como Argissolo Amarelo distrófico abrúptico (EMBRAPA, 2006), cuja caracterização física e química foi realizada em amostras coletadas nas camadas de 0-0,20, 0,21-0,40 e 0,41-0,60 m (Tabela 1).

O experimento foi conduzido utilizando-se onze variedades de cana-de-açúcar, sendo cinco variedades de maturação

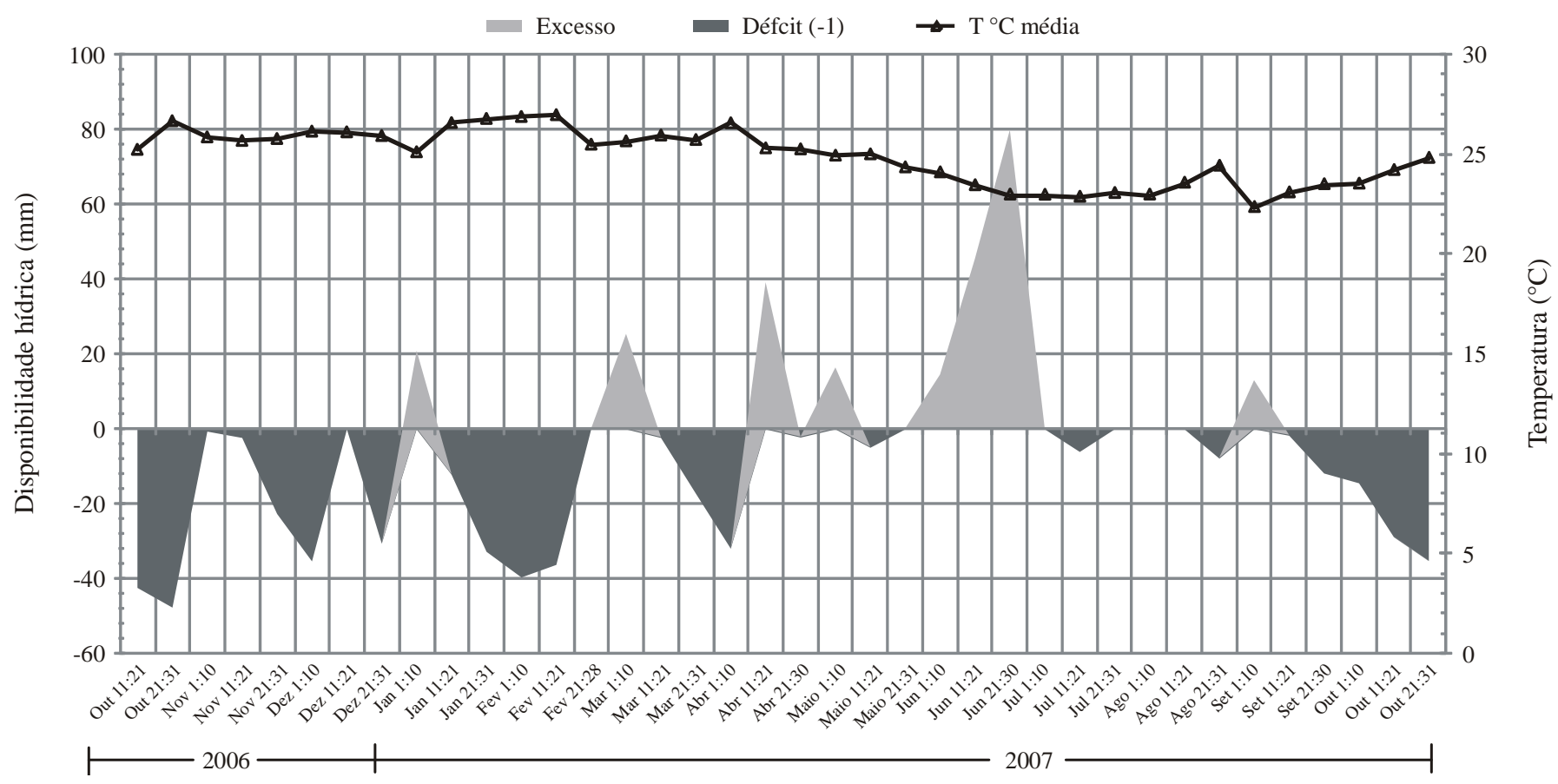

Figura 1. Balanço hídrico climatológico e temperatura média do ar durante a condução do experimento 
precoce (SP79-1011, RB813804, RB863129, RB872552 e RB943365) e seis de maturação média a tardia (RB72454, RB763710, SP78-4764, SP81-3250, RB867515 e RB92579). As variedades foram semeadas (colmo-semente) em parcelas constituídas de cinco sulcos de cana, espaçados a 1,10 m e com dez metros de comprimento. As parcelas foram distribuídas em delineamento experimental com quatro blocos ao acaso, perfazendo o total de 44 unidades experimentais.

Tabela 1. Caracterização química e física do solo da área experimental

\begin{tabular}{|c|c|c|c|}
\hline & \multicolumn{3}{|c|}{ Profundidade $(\mathrm{m})$} \\
\hline & $0,0-0,20$ & $0,21 \cdot 0,40$ & $0,41-0,60$ \\
\hline \multicolumn{4}{|c|}{ Propriedades químicas } \\
\hline $\mathrm{pH}\left(\mathrm{H}_{2} \mathrm{O}\right)$ & 5,4 & 5,2 & 5,0 \\
\hline $\mathrm{P}_{\text {Mehlich }}\left(\mathrm{mg} \mathrm{dm}^{-3}\right)$ & 8 & 7 & 6 \\
\hline $\mathrm{H}+\mathrm{Al}\left(\mathrm{cmol}_{\mathrm{c}} \mathrm{dm}^{-3}\right)$ & 6,4 & 6,8 & 6,8 \\
\hline $\mathrm{Al}\left(\mathrm{cmol}_{\mathrm{c}} \mathrm{dm}^{-3}\right)$ & 0,2 & 0,5 & 0,7 \\
\hline $\mathrm{Ca}\left(\mathrm{cmol}_{\mathrm{c}} \mathrm{dm}^{-3}\right)$ & 1,6 & 1,0 & 0,75 \\
\hline $\mathrm{Mg}\left(\mathrm{cmol}_{\mathrm{c}} \mathrm{dm}^{-3}\right)$ & 1,2 & 0,5 & 0,5 \\
\hline $\mathrm{K}\left(\mathrm{cmol}_{\mathrm{c}} \mathrm{dm}^{-3}\right)$ & 0,07 & 0,05 & 0,03 \\
\hline $\operatorname{CTC}^{(1)}\left(\mathrm{cmol}_{\mathrm{c}} \mathrm{dm}^{-3}\right)$ & 9,33 & 8,50 & 8,20 \\
\hline V $(\%)$ & 31,4 & 20,0 & 17,0 \\
\hline $\mathrm{m}(\%)$ & 6,3 & 22,7 & 26,1 \\
\hline \multicolumn{4}{|c|}{ Propriedades físicas } \\
\hline$\rho^{(I I)}\left(\mathrm{kg} \mathrm{m}^{-3}\right)$ & 1,44 & 1,36 & 1,39 \\
\hline Areia $\left(\mathrm{g} \mathrm{kg}^{-1}\right)$ & 769,4 & 689,4 & 661,0 \\
\hline Silte $\left(\mathrm{g} \mathrm{kg}^{-1}\right)$ & 61,4 & 46,4 & 54,8 \\
\hline Argila $\left(\mathrm{g} \mathrm{kg}^{-1}\right)$ & 169,2 & 264,2 & 284,2 \\
\hline$\theta_{\mathrm{cc}}\left(\mathrm{m}^{-3} \mathrm{~m}^{-3}\right)$ & 0,150 & 0,210 & 0,210 \\
\hline$\theta_{p m p}\left(m^{-3} m^{-3}\right)$ & 0,083 & 0,110 & 0,140 \\
\hline L. úti|(III) (mm) & 7,4 & 9,7 & 7,3 \\
\hline Textura & Franco arenosa & $\begin{array}{c}\text { Franco argilo- } \\
\text { arenosa }\end{array}$ & $\begin{array}{c}\text { Franco argilo- } \\
\text { arenosa }\end{array}$ \\
\hline
\end{tabular}

(I) Capacidade de troca de cátions potencial; (II) Densidade do solo; (III) Lâmina útil calculada a partir de $50 \%$ da lâmina total

O preparo do solo consistiu de gradagem para destruição dos restos culturais, previamente dessecados com herbicida (Glyphosate) e incorporação do calcário, seguindo-se a abertura dos sulcos de plantio. Para correção do solo utilizou-se calcário na dose de $465 \mathrm{~kg} \mathrm{ha}^{-1}$, calculado pelo método da neutralização do $\mathrm{Al}$ trocável ou elevação dos teores de Ca e $\mathrm{Mg}$ trocáveis, considerando-se $3,0 \mathrm{cmol}_{\mathrm{c}} \mathrm{dm}^{-3}$ como nível crítico de $\mathrm{Ca}+\mathrm{Mg}$.

$\mathrm{Na}$ adubação de plantio aplicaram-se, no fundo do sulco, $30 \mathrm{~kg} \mathrm{ha}^{-1}$ de $\mathrm{N} ; 120 \mathrm{~kg} \mathrm{ha}^{-1}$ de $\mathrm{P}_{2} \mathrm{O}_{5}$ e $70 \mathrm{~kg} \mathrm{ha}^{-1}$ de $\mathrm{K}_{2} \mathrm{O}$, respectivamente, na forma de sulfato de amônio (SA), cloreto de potássio $(\mathrm{KCl})$ e superfosfato triplo (SFT). Aos 90 dias após o plantio (DAP), realizou-se a adubação de cobertura aplicando-se $50 \mathrm{~kg} \mathrm{ha}^{-1}$ de $\mathrm{N}$ e $50 \mathrm{~kg} \mathrm{ha}^{-1}$ de $\mathrm{K}_{2} \mathrm{O}$ nas linhas da cana-de-açúcar seguida de incorporação manual utilizando-se respectivamente, o SA e o $\mathrm{KCl}$ como fonte dos nutrientes. A calagem e a adubação do solo tiveram como base os resultados da análise do solo (Tabela 1) e o Manual de recomendações de adubação para o estado de Pernambuco (IPA, 1998).

Adotou-se o manejo de irrigação plena até os 300 DAP, aplicando-se uma lâmina calculada para suprir a evapotranspiração da cultura (Etc) até $0,6 \mathrm{~m}$ de profundidade (Tabe- la 1). Para tanto, levaram-se em consideração os resultados da capacidade de campo (CC) e do ponto de murcha permanente (PMP) do solo até profundidade amostrada (Tabela 1), bem como a precipitação e a eficiência (75\%) do sistema de irrigação utilizado.

A ETc foi calculada segundo a equação: $\mathrm{ETc}=\mathrm{ECA}$ x Kp x Kc, em que: Etc: evapotranspiração da cultura (mm); ECA: evaporação do tanque Classe A (mm), que se encontrava localizado próximo à área experimental; $\mathrm{Kp}=$ coeficiente do tanque Classe A, que possuía bordadura de $10 \mathrm{~m} \mathrm{e}$ Kc: coeficiente de cultura. Os valores de coeficientes de cultura seguiram os diversos estádios de desenvolvimento da cana-de-açúcar, sendo utilizados gradativamente os valores de $0,55,0,8,1,0,1,25,1,0$ e 0,6 ; respectivamente na germinação, perfilhamento, estabelecimento do "stand", crescimento elevado ou elongação do colmo, senescência das folhas e maturação (Inman-Bamber \& McGlinchey, 2003; Bernardo et al., 2005). Na reposição da lâmina utilizou-se o sistema de aspersão convencional do tipo canhão móvel, com bocal de quatro polegadas de diâmetro e vazão (Q) de $54 \mathrm{~m}^{3} \mathrm{~h}^{-1}$ sob pressão de $40 \mathrm{~m}$ de coluna de água (mca).

$\mathrm{O}$ crescimento foi avaliado mensalmente nas três linhas centrais de cada parcela experimental, quantificando-se o número de plantas em oito metros de comprimento (perfilhamento), e se contabilizando os dados de altura e diâmetro do colmo em dez plantas previamente identificadas. A altura do colmo foi mesurada com auxílio de uma fita métrica, a partir do solo até o colarinho da folha $(+1)$ e o diâmetro do colmo foi dimensionado utilizando-se paquímetro no terço médio da planta. A folha $(+1)$ foi considerada como aquela que apresentava o primeiro colarinho totalmente visível.

A produção de matéria seca da parte aérea das variedades foi avaliada aos 120, 180, 240, 300 e 360 DAP, utilizando-se oito plantas em cada parcela experimental. As amostras foram separadas em ponteiro, folha e colmo, sendo o ponteiro constituído do cartucho e da folha $(+1)$; no componente folha (folha + bainha), consideraram-se as folhas secas e verdes a partir da folha $(+1)$ e, após a retirada do ponteiro e das folhas, o restante foi considerado colmo.

Depois de separados, os ponteiros, folhas e colmos, foram pesados, determinando-se a matéria fresca e em seguida, triturados em forrageira e subamostrados. Nas subamostras determinou-se a umidade após serem secadas em estufa de circulação forçada de ar a $65^{\circ} \mathrm{C}$ até peso constante. Descontada a umidade, a massa por hectare de matéria seca foi calculada multiplicando-se o perfilhamento pela matéria seca obtida nos componentes; ponteiro, folha e colmo em cada período de amostragem.

Os dados obtidos foram submetidos à análise de variância utilizando-se o teste $\mathrm{F}$, a $5 \%$ de probabilidade. Para as variáveis significativas foram ajustadas regressões em função do período de crescimento e acúmulo de matéria seca de cada variedade avaliada. Como critérios para a escolha dos modelos de regressão, selecionaram-se os modelos que apresentaram maior coeficiente de determinação e significância dos parâmetros da regressão até $5 \%$ de probabilidade pelo teste $t$. 


\section{RESULTADOS E DISCUSSÃO}

\section{Perfilhamento}

O perfilhamento mostrou diferença entre as variedades durante as épocas avaliadas observando-se, nas SP81-3250 e RB92579, os maiores números de perfilhos (Figura 2B). Nas variedades de maturação precoce o perfilhamento máximo ocorreu aos 90 DAP (Figura 2A), enquanto nas variedades de maturação média a tardia, verificou-se que o perfilhamento máximo ocorreu aos $60 \mathrm{DAP}$, exceto para as RB72454 e SP78-4764, que apresentaram a máxima densidade média de plantas aos 90 DAP (Figura 2B).

Independente da diferença observada entre as variedades com relação ao perfilhamento máximo, que ocorreu entre 60 e 90 DAP constatou-se, em média, redução de $50 \%$ nos perfilhos até o momento da colheita, exceto nas variedades RB863129 e SP78-4764 que apresentaram a maior e a menor redução, com valores de 68 e $42 \%$, respectivamente. De acordo com Castro (2000); Oliveira et al., (2004), o perfi-

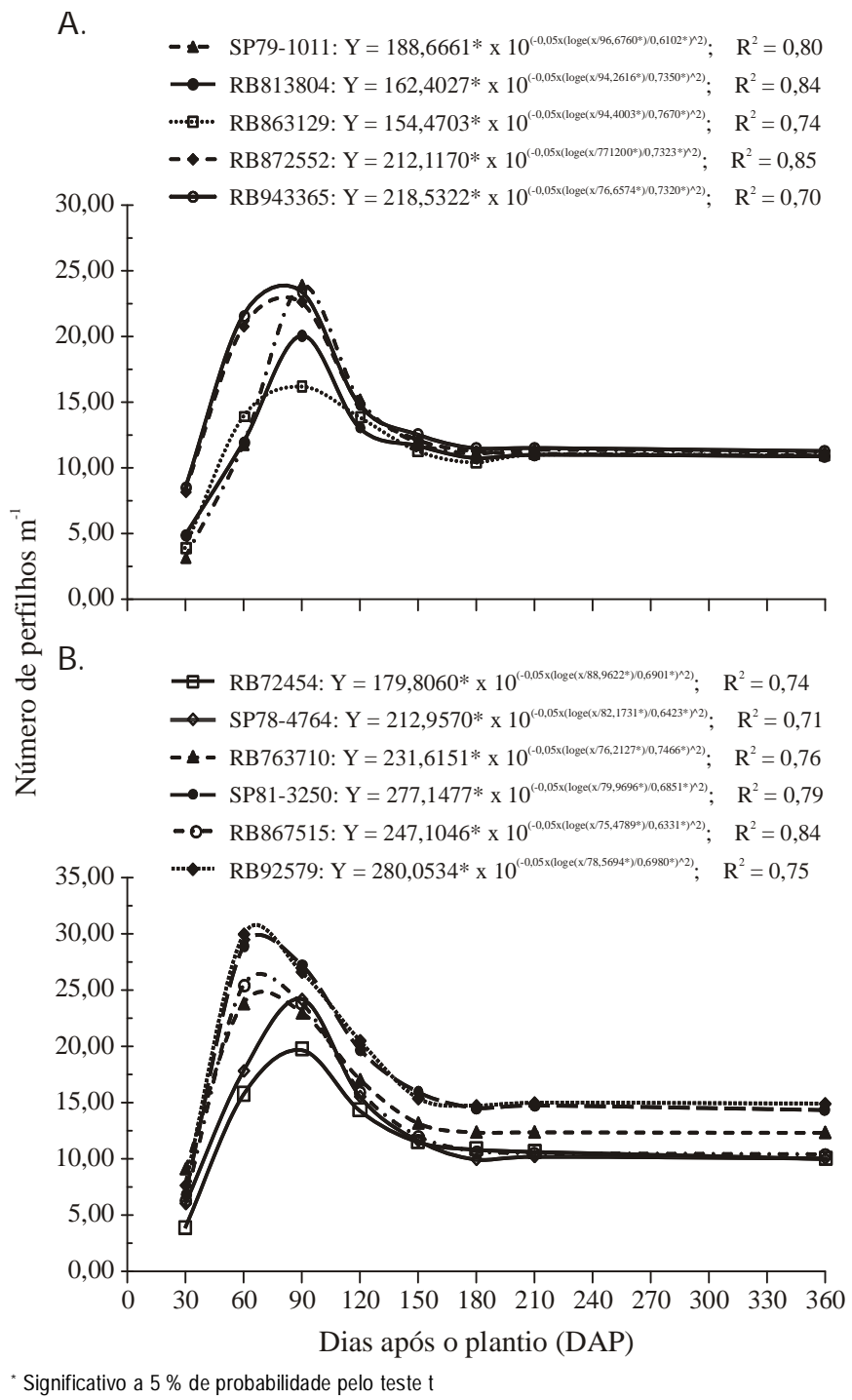

Figura 2. Número de plantas por metro (perfilhamento) relacionado ao tempo em variedades de cana-de-açúcar com maturação precoce (A) e de maturação média a tardia (B) lhamento na cana-de-açúcar é crescente até o sexto mês após o plantio e a partir deste período, se inicia uma redução no número de perfilhos, decorrente da competição, por luz, área, água e nutrientes refletindo, assim, na diminuição e paralisação do processo, além da morte dos perfilhos mais jovens; apesar disto, verificou-se que os altos perfilhamentos de 30 e 29 plantas por metro linear, aos 60 DAP obtidos, respectivamente, pelas variedades RB92579 e SP81-3250, não influenciaram na diminuição dos perfilhos, sendo observada redução média de $50 \%$ o que proporcionou, a essas variedades, $25 \%$ a mais de plantas por metro, aos 360 DAP, em relação às demais variedades.

A alta densidade de perfilhos por metro linear aos $60 \mathrm{e}$ 90 DAP, encontrada neste estudo, foi superior à obtida por outros pesquisadores (Marques et al., 2005; Oliveira et al., 2005; Almeida et al., 2008). Possivelmente, esses resultados se devem as condições de umidade contínuas do solo mantidas pela irrigação plena, associadas às temperaturas acima de $25^{\circ} \mathrm{C}$, que ocorreram durante o experimento (Figura 1). Segundo Bonnet et al. (2006), à medida em que a temperatura do ar se eleva até em torno de $30{ }^{\circ} \mathrm{C}$ há aumento considerável de perfilhamento e crescimento em altura, favorecendo maior propagação vegetativa da cana-de-açúcar.

\section{Altura do colmo}

No que se refere à altura do colmo obteve-se ajuste sigmoidal, caracterizando três fases de desenvolvimento (Figuras 3A e C): a primeira fase de crescimento foi semelhante para todas as variedades estudadas, observando-se pequeno aumento de estatura até os $60 \mathrm{DAP}$, com valores médios de $18 \mathrm{~cm}$; na segunda fase de crescimento, que ocorreu entre os 60 e 240 DAP, verificaram-se diferenças entre as variedades e as maiores taxas de crescimento em altura do colmo (TCA) que ocorreram entre 120 e $150 \mathrm{DAP}$, com valores médios de $22 \mathrm{~mm} \mathrm{~d}^{-1}$ (Figuras 3B e D). No final da segunda fase de crescimento as variedades de maturação precoce RB872552 e RB863129 obtiveram, respectivamente, as maiores alturas, com valores de 310 e $291 \mathrm{~cm}$ (Figura 3A). Para as variedades de maturação média tardia, as RB92579 SP78-4764, RB763710 e RB867515 apresentaram os maiores crescimentos em altura do colmo, com valores de 311, 307, 306 e $304 \mathrm{~cm}$, respectivamente (Figura 3C); na terceira fase de crescimento as variedades obtiveram ganhos médios de $49 \mathrm{~cm}$, o que representou $15 \%$ da altura total do colmo; nesta fase se observaram, nas variedades RB72454 e RB813804, os maiores crescimentos finais, com valores superiores aos $350 \mathrm{~cm}$, enquanto a variedade SP79-1011 apresentou o menor valor de crescimento, ou seja, com média de $258 \mathrm{~cm}$ (Figura 3A e B).

Os baixos crescimentos em altura obtidos pela variedade SP79-1011 com uso da irrigação, também foram verificados por Carvalho et al. (2009) na zona canavieira da Paraíba, ao observarem valores médios de $221 \mathrm{~cm}$ e ganhos de $30 \mathrm{~cm}$ em relação ao manejo não irrigado. Outro estudo realizado na mesma região produtora, apresentou valores finais ainda menores $(153 \mathrm{~cm})$ e acréscimo de apenas $4 \mathrm{~cm}$ na altura do colmo em comparação com o cultivo de sequeiro (Farias et al., 2008). 
A.

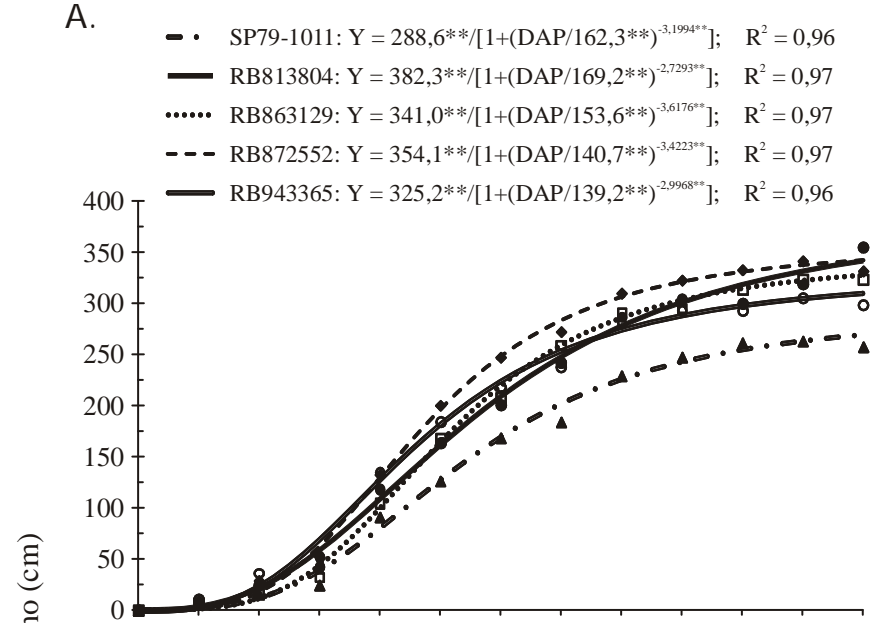

C.
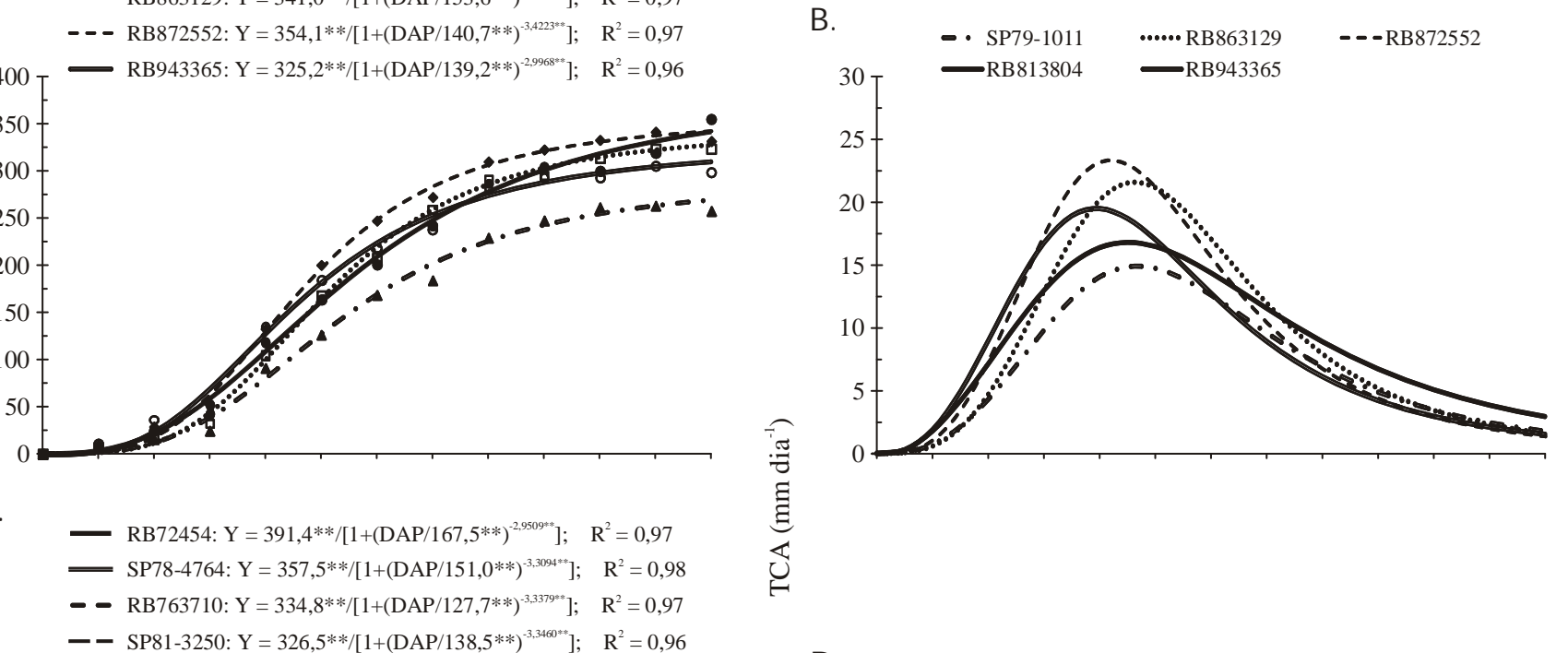

-. RB867515: $\mathrm{Y}=370,5^{* *} /\left[1+(\mathrm{DAP} / 148,1 * *)^{-22120^{* *}}\right] ; \quad \mathrm{R}^{2}=0,97$

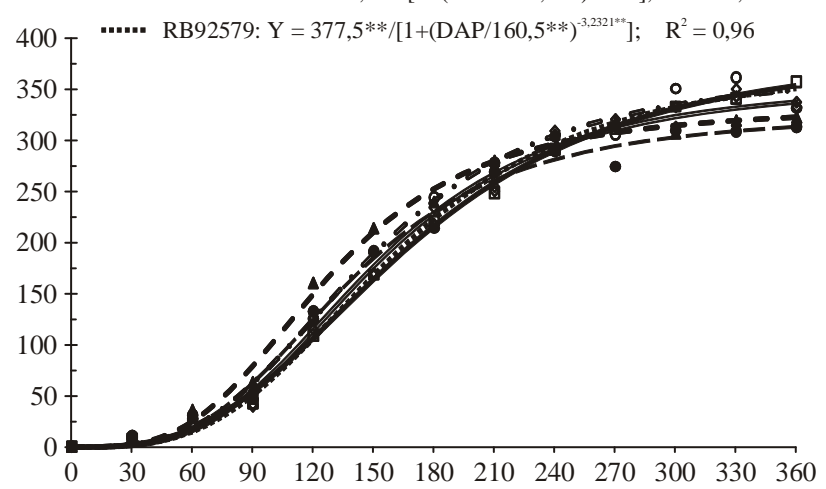

\section{D.}

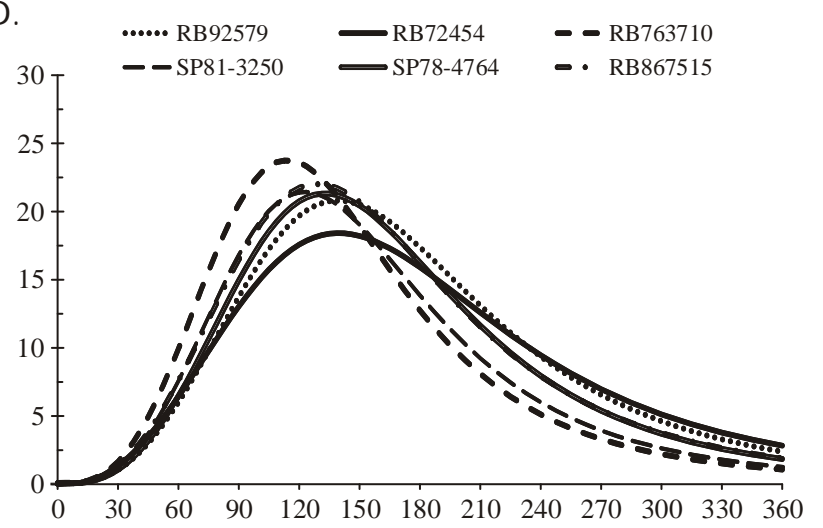

Dias após o plantio (DAP)

${ }^{* *}$ Significativo a $1 \%$ de probabilidade pelo teste $\mathrm{t}$

Figura 3. Altura do colmo e taxa de crescimento em altura (TCA) relacionada ao tempo em variedades de cana-de-açúcar de maturação precoce (A e B) e de maturação média a tardia (C e D)

As primeira e segunda fases de crescimento foram responsáveis por $85 \%$ da altura total do colmo da cana-de-açúcar entre variedades avaliadas, ou seja, as duas primeiras fases de crescimento ocorreram entre os meses de outubro a junho, período caracterizado por baixa precipitação, maior intensidade de luz e temperaturas mais elevadas que, associadas à disponibilidade hídrica promovida pela irrigação plena, resultaram, em ganhos médios de $280 \mathrm{~cm}$ em altura do colmo. Na região centro sul do Brasil, Oliveira et al. (2004) notaram, em variedades não irrigadas, os maiores ganhos em altura do colmo entre os meses de dezembro a março, com taxas médias de crescimento de $1,7 \mathrm{~cm} \mathrm{~d}^{-1}$, proporcionando estaturas finais de colmo de $326 \mathrm{~cm}$, valores semelhantes aos observados neste estudo.

\section{Diâmetro do colmo}

Para o diâmetro do colmo os dados também se ajustaram ao modelo sigmóide, caracterizando duas fases de desenvolvimento (Figuras 4A e C), em que na primeira fase, o aumento no diâmetro do colmo foi rápido e constante nos primeiros 90 dias, apresentando taxas médias de crescimento em diâmetro do colmo (TCD) de $0,22 \mathrm{~mm} \mathrm{~d}^{-1}$ (Figuras 4B e D) e média final entre as variedades de $19 \mathrm{~mm}$. O crescimento inicial do diâmetro do colmo diferiu entre as variedades sendo observado, nas RB763710, RB867515, RB863129, RB872552 e RB913365, que a primeira fase permaneceu até os 60 DAP e nas RB72454, RB92579, SP78-4764, SP81-3250, RB813804 e SP79-1011 até os 90 DAP (Figuras 4A e C); na segunda fase o diâmetro do colmo da cana-de-açúcar apresentou pequeno aumento em espessura, obtendo-se valores médios finais de $25 \mathrm{~mm}$; entre as variedades, as RB72454 e RB867515 de maturação média a tardia, obtiveram os maiores diâmetros aos 360 DAP, com valor médio de $27 \mathrm{~mm}$ (Figura 4C). Resultados semelhantes foram obtidos por Silva (2007), ao avaliar o diâmetro do colmo em diferentes variedades, que também constatou, nas RB867515 e RB72454, aos 360 DAP, os maiores diâmetros dentre as variedades estudadas, com valores de 27 e $26 \mathrm{~mm}$, respectivamente. 
A.

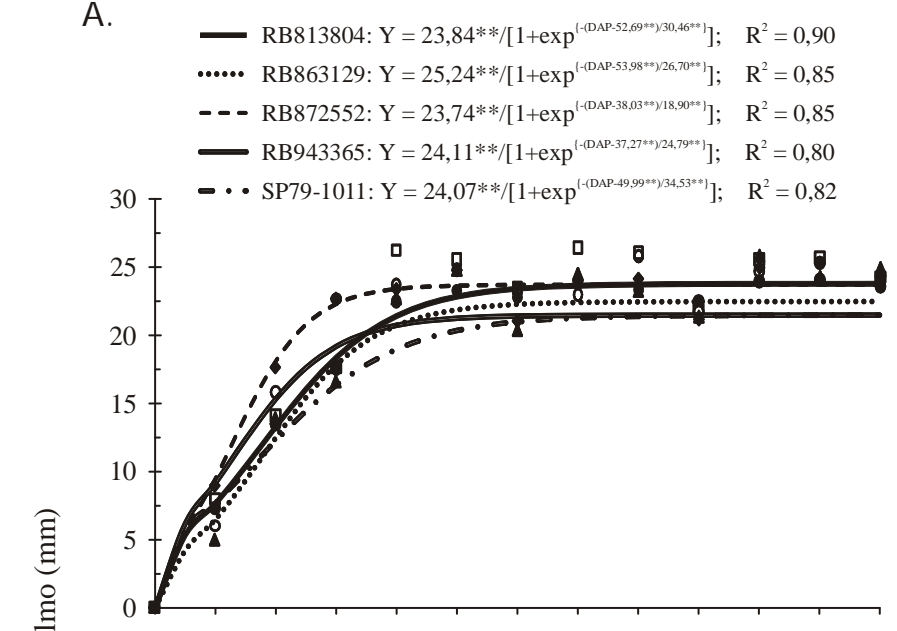

C.
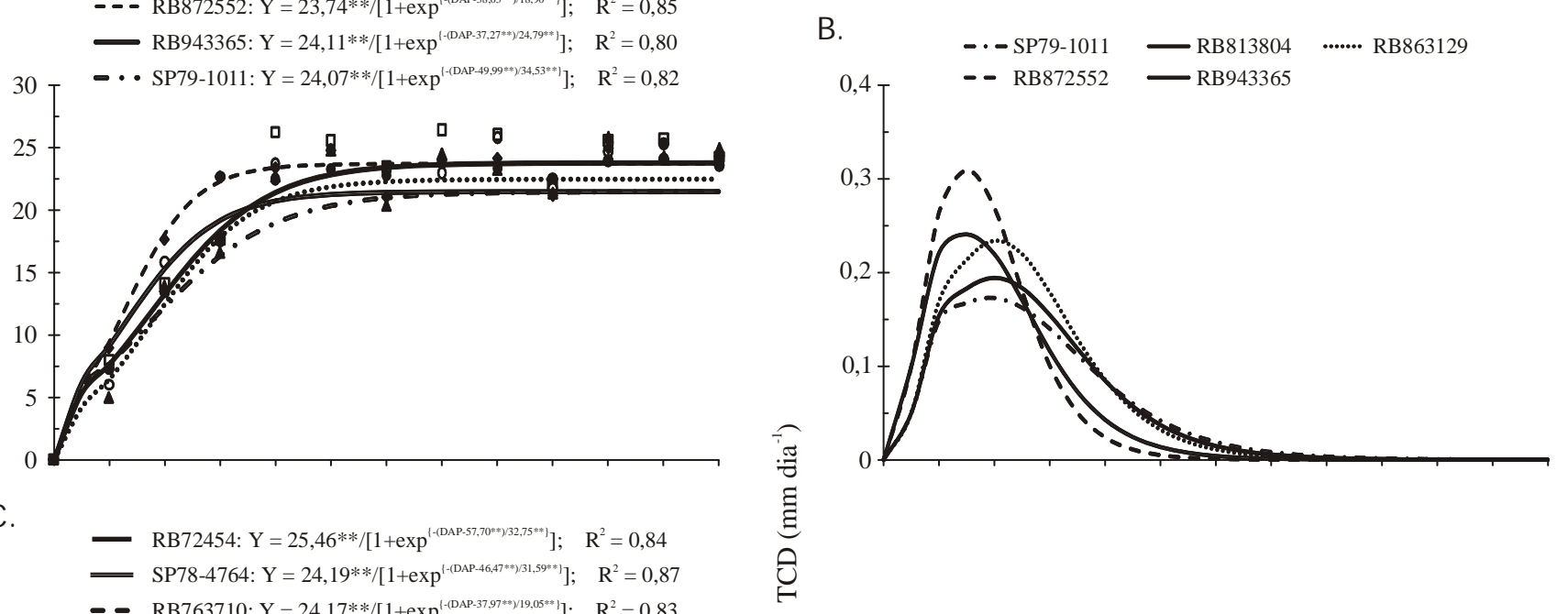

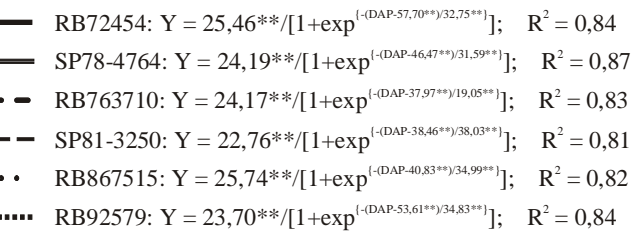
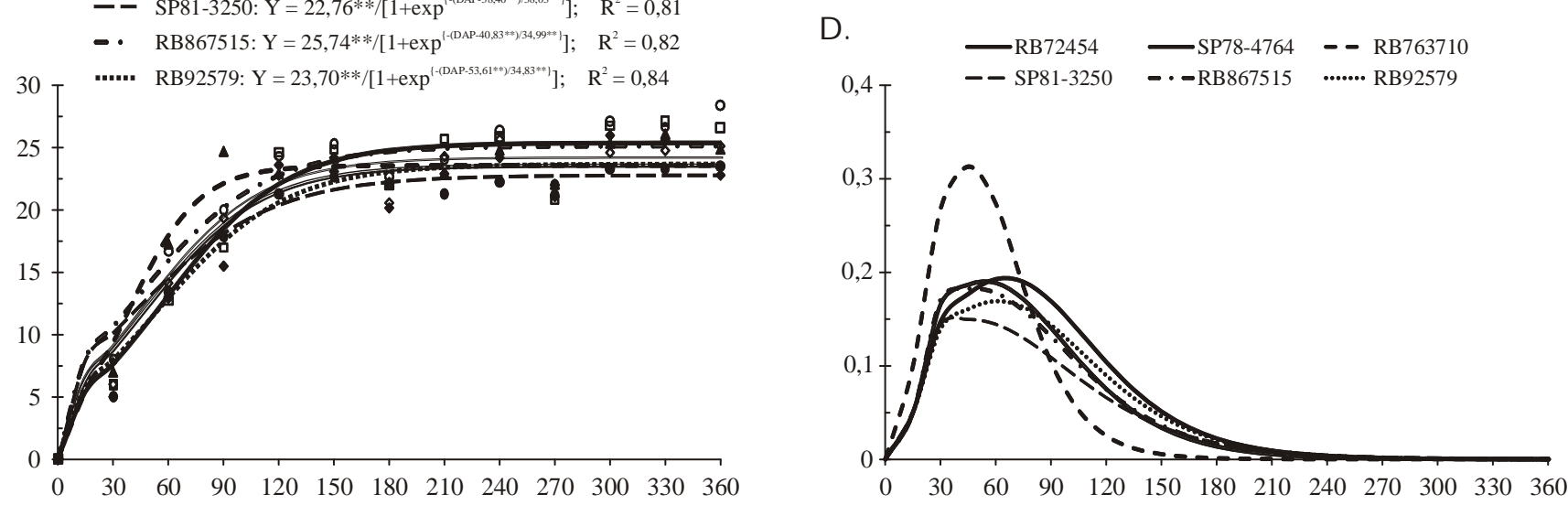

Dias após o plantio (DAP)

** Significativo a $1 \%$ de probabilidade pelo teste $\mathrm{t}$

Figura 4. Diâmetro do colmo e taxa de crescimento em diâmetro (TCD) relacionados ao tempo em variedades de cana-de-açúcar de maturação precoce $(A$ e $B$ ) e de maturação média a tardia ( $C$ e $D$ )

\section{Matéria seca de parte aérea}

Com relação ao acúmulo de matéria seca na parte aérea da cana-de-açúcar, os resultados também diferiram entre as variedades avaliadas, obtendo-se ajuste quadrático para matéria seca da folha + ponteiro e ajuste sigmoidal para a matéria seca do colmo (Figuras 5 e 6). Observou-se que até os 120 DAP a matéria seca da folha + ponteiro foi superior em relação à do colmo, ocorrendo, a partir desta fase, inversão na quantidade de matéria seca acumulada no colmo que passou a ser superior à acumulada na folha + ponteiro, mantendo-se superior até o final do ciclo da cultura.

De acordo com Machado et al. (1982) após 100 dias de cultivo a matéria seca das folhas e ponteiro representa $70 \%$ de toda a biomassa da planta; depois deste período ocorre diminuição progressiva no acúmulo de matéria seca neste componente até próximo aos 400 DAP, representando apenas $9 \%$ da matéria seca acumulada pela planta. Acúmulo de matéria seca na parte aérea da cana-de-açúcar foi obtido por Silva (2007) e Orlando Filho et al. (1980) os quais mostraram que a matéria seca acumulada na folha + ponteiro foi superior à do colmo até os 180 e 300 DAP, respectivamente, sendo esses períodos superiores aos observados neste estudo.

O maior acúmulo de matéria seca no colmo a partir dos 120 DAP é resultante provavelmente,do manejo hídrico do solo utilizado neste estudo. Como as variedades foram conduzidas sobregime hídrico plenonas fases de germinação, perfilhamento e início de alongamento de colmo (fase de maior crescimento) não houve deficiência hídrica, o que promoveu crescimento contínuo e, provavelmente, formação antecipada de colmos.

Nas variedades precoces a quantidade de matéria seca acumulada na folha + ponteiro foi constante ao longo do tempo, com valores médios variando entre 7,5 e 12,0 $\mathrm{Mg} \mathrm{ha}^{-1}$ (Figura 5), evidenciando que o acúmulo de matéria seca total por essas variedades depende do acúmulo obtido pelo colmo. Para as variedades de maturação média a tardia, RB72454, SP78-4764, RB867515, SP81-3250 e RB92579, o acúmulo máximo estimado de matéria seca na folha + ponteiro ocorreu aos 240 DAP, com exceção da variedade RB763710, em que o acúmulo de matéria seca foi constante e apresentou valor médio de 12,0 $\mathrm{Mg} \mathrm{ha}^{-1}$ (Figura 6). 
SP79-1011

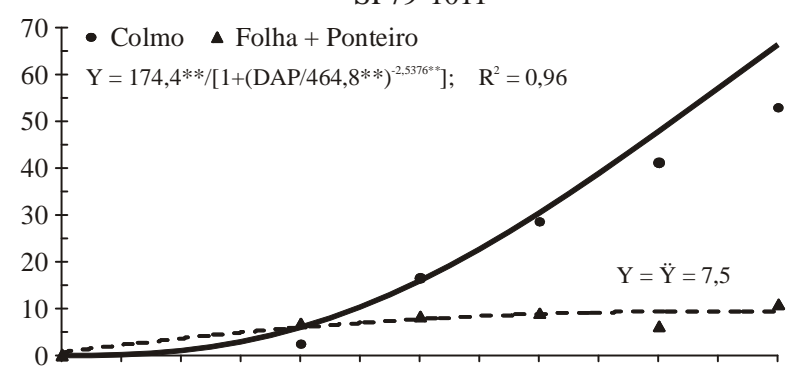

SP813804

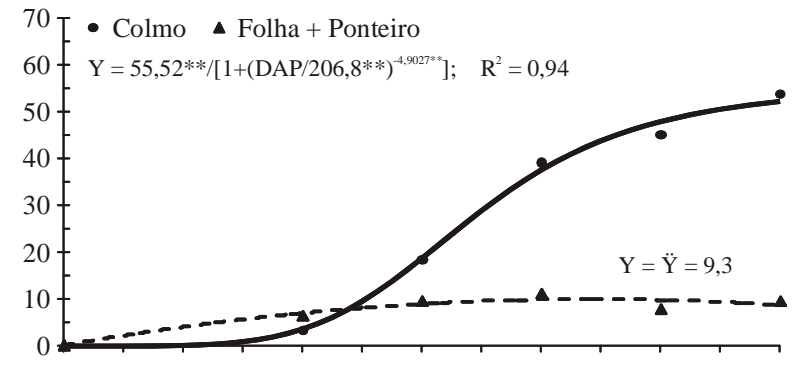

RB863129

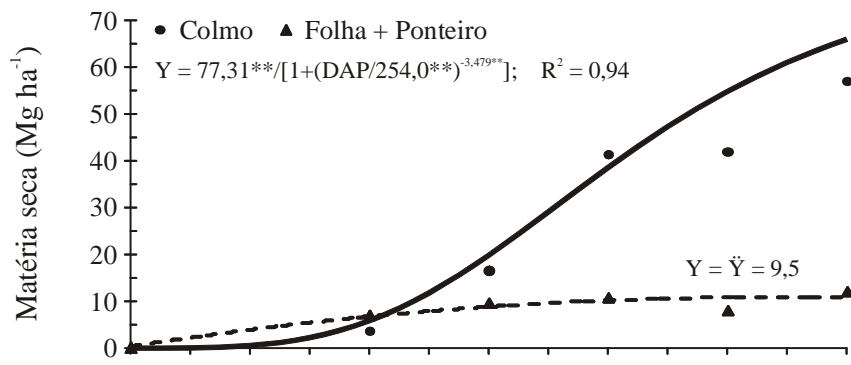

RB872552

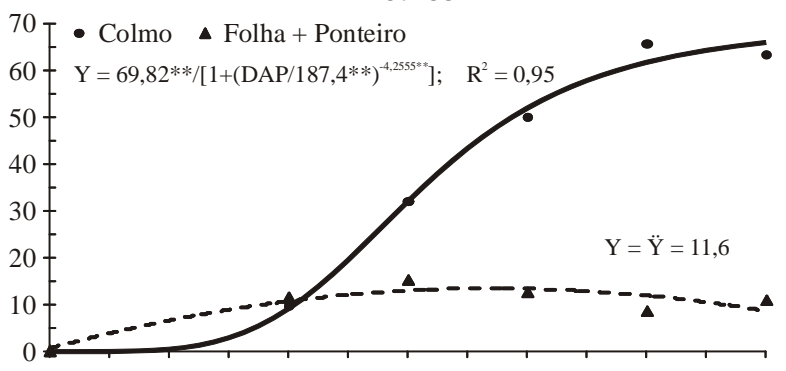

RB943365

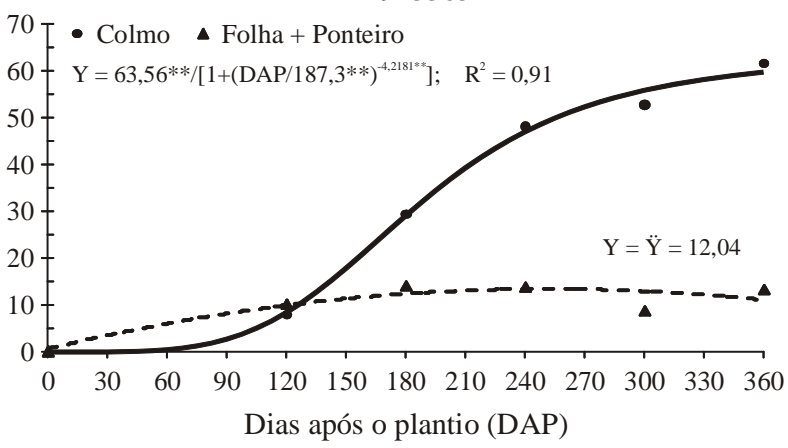

" Significativo a $1 \%$ de probabilidadepelo teste $t$

Figura 5. Acúmulo de matéria seca no colmo e na folha + ponteiro relacionado ao tempo em diferentes variedades de cana-de-açúcar de maturação precoce
Neste estudo se observou que o acúmulo de matéria seca no colmo se caracterizou em três fases de desenvolvimento (Figuras 5 e 6); a primeira fase foi observada até os 120 DAP, acumulando em média na parte aérea $8 \mathrm{Mg} \mathrm{ha}^{-1}$, com destaque para a variedade de maturação média tardia RB763710 e de maturação precoce RB872552 que acumularam, respectivamente, 14 e $10 \mathrm{Mg} \mathrm{ha}^{-1}$ no primeiro período de desenvolvimento, enquanto na segunda fase de desenvolvimento o acúmulo de matéria seca do colmo mostrou-se mais elevado e apresentou diferenças entre as variedades, promovendo a formação de três grupos distintos, o primeiro formado pelas variedades RB872552, RB943365, RB763710, SP78-4764 e RB867515 obtiveram, entre o final da primeira fase até os 300 DAP, taxas médias de acúmulo de matéria seca do colmo (TPMSC) de $256 \mathrm{~kg} \mathrm{ha}^{-1} \mathrm{~d}^{-1}$ (Figura 7A e B), proporcionando valores médios de $48 \mathrm{Mg} \mathrm{ha}^{-1}$ de matéria seca acumulada no final desse período; no segundo grupo, constituído das variedades SP81-3250, RB72454 e RB813804, os máximos acúmulos ocorreram até os 330 DAP, constatando-se TPMSC média de $245 \mathrm{~kg} \mathrm{ha}^{-1} \mathrm{~d}^{-1}$ e produções finais de $49 \mathrm{Mg} \mathrm{ha}^{-1}$. Observou-se, para os dois grupos de variedades formados, que esta fase representou, respectivamente, 83 e $77 \%$ de toda a matéria seca acumulada no colmo. Para terceiro grupo, formado pelas variedades RB92579, RB863129 e SP79-1011, não foi possível determinar o final do segundo período de acúmulo de matéria seca do colmo, evidenciando que o ganho em matéria seca neste componente permaneceria crescente após os 360 DAP.

$\mathrm{Na}$ terceira fase as variedades de maturação precoce RB872552 e RB943365 se destacaram das demais, com acúmulos finais de $62 \mathrm{Mg} \mathrm{ha}^{-1}$ de matéria seca do colmo (Figura 5); nas variedades de maturação média a tardia, os maiores acúmulos foram obtidos pelas RB92579 e SP81-3250, com produções de 85 e $72 \mathrm{Mg} \mathrm{ha}^{-1}$ de matéria seca do colmo, respectivamente (Figura 6), resultados que mostram claramente a alta resposta dessas variedades ao manejo da irrigação nas condições edafoclimáticas do nordeste brasileiro. Por outro lado, se constataram, nas variedades de maturação precoce RB813804 e SP79-1011, as menores respostas à irrigação plena, sendo observados, respectivamente, acúmulos pelo colmo, inferiores a $55 \mathrm{Mg} \mathrm{ha}^{-1}$.

A produção de matéria seca total da parte aérea, aos 360 DAP, se diferenciou entre as variedades estudadas (Figura 8), constatando-se a variedade RB92579 como a mais produtiva, com acúmulo de $97 \mathrm{Mg} \mathrm{ha}^{-1}$, seguida da SP81-3250, que obteve acúmulo médio de $85 \mathrm{Mg} \mathrm{ha}^{-1}$. A maior produtividade obtida pela variedade RB92579 se deve à elevada e contínua TPMSC média de $232 \mathrm{~kg} \mathrm{ha}^{-1} \mathrm{~d}^{-1}$ (Figura 7B), o que levou a acúmulos finais de $85 \mathrm{Mg} \mathrm{ha}^{-1}$ de matéria seca de colmo (Figura 6), resultados que corroboram com os obtidos por Almeida et al. (2008) que também observaram, na variedade RB92579, os maiores acúmulos de matéria seca no colmo porém com produção de $30 \mathrm{Mg} \mathrm{ha}^{-1}$ inferior à observada neste estudo.

O acúmulo de matéria seca no colmo revelados pela variedade RB92579 estão relacionados, possivelmente ao potencial genético de perfilhamento dessa variedade 

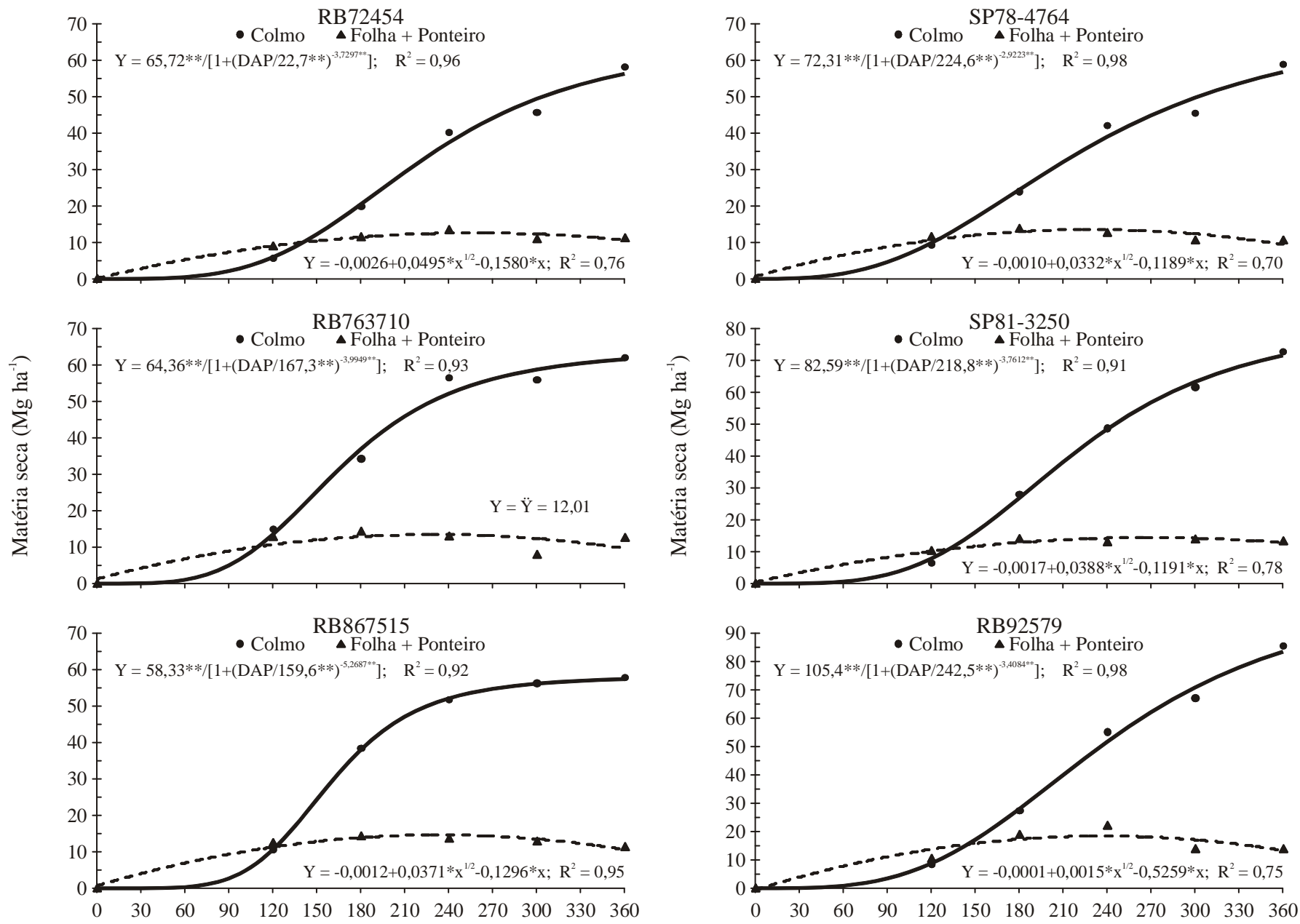

Dias após o plantio (DAP)

* $e^{* *}$ Significativo a 5 e $1 \%$ de probabilidade, respectivamente, pelo teste $t$

Figura 6. Acúmulo de matéria seca no colmo e na folha + ponteiro relacionado ao tempo em diferentes variedades de cana-de-açúcar de maturação média a tardia

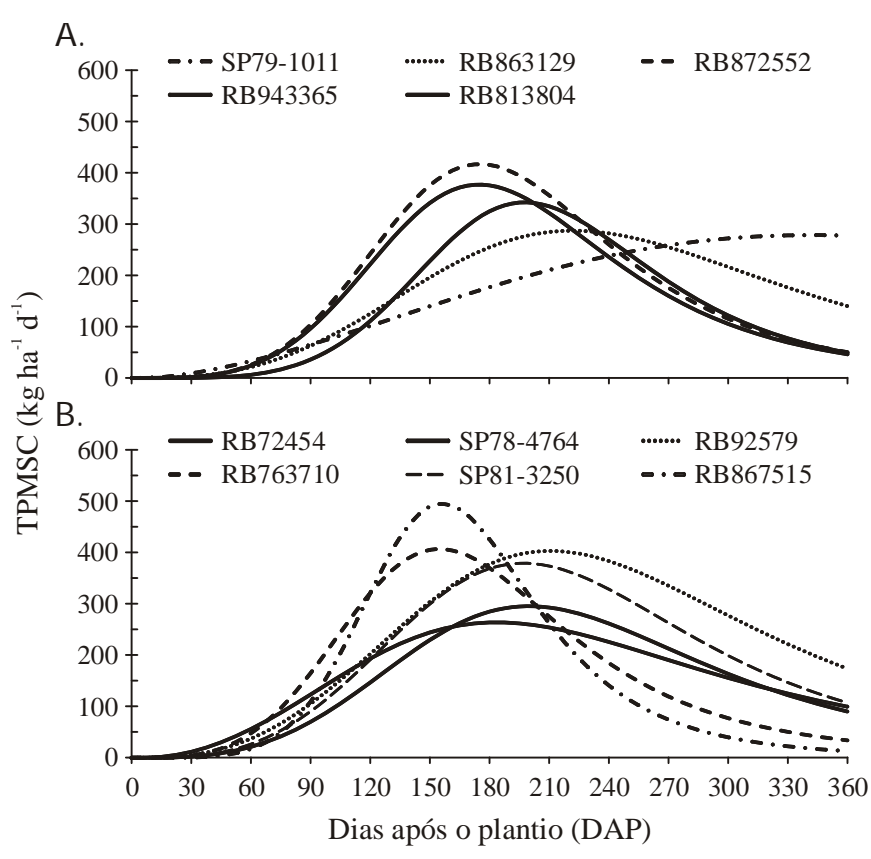

Figura 7. Taxa de produção de matéria seca do colmo (TPMSC) relacionada ao tempo em diferentes variedades de cana-de-açúcar de maturação precoce (A) e de maturação média tardia (B)

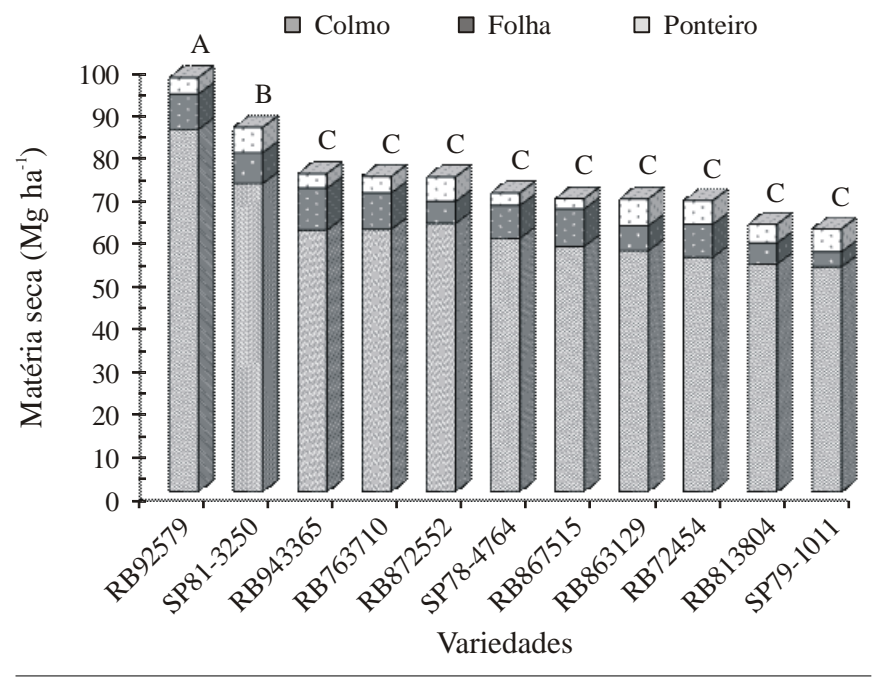

Figura 8. Acúmulo de matéria seca total (colmo + folha + ponteiro) em diferentes variedades de cana-de-açúcar (Teste de Scott-Knott a $5 \%$ de probabilidade)

(Figura 2B), além de seu potencial de crescimento em altura (Figura $3 \mathrm{C}$ ). O rápido crescimento e o desenvolvimento na fase de perfilhamento da cana-de-açúcar requerem elevada disponibilidade hídrica e temperatura elevada, tal 
como características morfológicas que favoreçam a interceptação da radiação solar (Bonnett et al., 2006; Terauchi \& Matsuoka, 2000); desta forma a irrigação plena associada a temperaturas ideiais (Figura 1) na fase de perfilhamento e o máximo crescimento promoveram, na variedade RB92579, o desenvolvimento de todo o potencial genético, confirmando sua alta capacidade em captar radiação solar e convertê-la em matéria seca.

Por fim, a menor produção de matéria seca da parte aérea e o menor crescimento em altura do colmo observado na variedade SP79-1011, quando associados aos resultados de altura, diâmetro e produção de biomassa encontrados em condições edafoclimáticas semelhantes às ao do presente estudo (Farias et al., 2008; Carvalho et al., 2009; Silva et al., 2009), mostram claramente a baixa resposta desta variedade incremento hídrico no solo, tornando-a indesejável para áreas irrigadas e inaplicável em estudos comparativos de resposta à irrigação na cultura da cana-de-açúcar, o que vem subestimando os resultados obtidos em outras pesquisas.

\section{CONCLUSÕES}

1. A disponibilidade hídrica promovida pela irrigação plena durante as fases de desenvolvimento da cana-de-açúcar, proporciona diferença no perfilhamento, crescimento em altura e acúmulo de matéria seca entre variedades; contudo, pouca influência é observada no diâmetro do colmo.

2. A variedade de maturação precoce SP79-1011, por apresentar o menor crescimento em altura e baixa produção de matéria seca, torna-se inadequada para áreas irrigadas, devendo ser substituída por outras variedades precoces, como as RB943365 e RB872552.

3. A variedade de maturação média a tardia RB92579, apesar de não apresentar altura e diâmetro superiores aos das demais variedades avaliadas, mostra-se a mais produtiva, evidenciando que outras características morfológicas, como o perfilhamento e índice de área foliar, podem ser mais decisivas na produção final de matéria seca.

\section{LITERATURA CITADA}

Almeida, A. C. S.; Souza, J. L.; Teodoro, I.; Barbosa, G. V. S; Moura Filho, G.; Ferreira Júnior, R. A. Desenvolvimento vegetativo e produção de variedades de cana-de-açúcar em relação à disponibilidade hídrica e unidades térmicas. Ciência e Agrotecnologia, v.32, n.5, p.1441-1448, 2008.

Bernardo, S.; Soares, A. A. E.; Mantovane, E. C. Manual de irrigação. Viçosa: UFV. 2005. 611p.

Bonnett, G. D.; Hewitt, M. L.; Glassop, D. Effects of high temperature on the growth and composition of sugarcane internodes. Australian Journal of Agricultural Reseach, v.57, p.1087-1095, 2006.
Carvalho, C. M.; Azevedo, H. M. de; Dantas Neto, J.; Silva, C. T., S.; Gomes Filho, R. R.; Valnir Júnior, M. Influência de diferentes níveis de irrigação sobre os parâmetros organográficos da cana-de-açúcar. Revista Brasileira de Ciências Agrárias, v.4, n.2, p.173-178, 2009.

Castro, P. R. C. Aplicações da fisiologia vegetal no sistema de produção da cana-de-açúcar. In: Simpósio Internacional de Fisiologia da Cana-de-açúcar, 2000, Piracicaba. Anais... Piracicaba: STAB, 2000, p.1-9.

EMBRAPA - Empresa Brasileira de Pesquisa Agropecuária. Sistema brasileiro de classificação de solos. 2.ed. Rio de Janeiro: Embrapa Solos, 2006. 306p.

Farias, C. H. A. de.; Fernandes, P. D.; Azevedo, H. M. de.; Dantas Neto, J. Índice de crescimento da cana-de-açúcar irrigada e de sequeiro no Estado da Paraíba. Revista Brasileira de Engenharia Agrícola e Ambiental, v.12, n.4, p.356-362. 2008.

Gava, G. J. C.; Trivelin, P. C. O.; Oliveira, M.W.; Penatti, C. P. Crescimento e acúmulo de nitrogênio em cana-de-açúcar cultivada em solo coberto com palhada. Pesquisa Agropecuária Brasileira, v.36, n.11, p.1347-1354, 2001.

Inman-Bamber, N. G.; McGlinchey, M. G. Crop coefficients and water use estimates for sugarcane based on long-term Bowen ratio energy balance measurements. Field Crops Research, v.83, p.125-138, 2003.

Inman-Bamber, N. G.; Muchow, R. C.; Robertson, M. J. Dry partitioning of sugarcane in Australia and South Africa. Field Crops Research, v.76, p.71-84, 2002.

IPA - Empresa Pernambucana de Pesquisa Agropecuária. Cavalcanti, F. J. A. Recomendações de adubação para o estado de Pernambuco. 2.ed. Cavalcanti, F. J. A. (ed.). $2^{\mathrm{a}}$ aproximação, Recife: IPA, 1998, 198p.

Machado, E. C.; Pereira, A. R.; Fahl, J. I.; Arruda, J. V.; Cione, J. Índices biométricos de duas cultivares de cana-de-açúcar. Pesquisa Agropecuária Brasileira, v.17, n.9, p.1323-1329, 1982.

Marques, T. A.; Godinho, A. M. M.; Almeida, R. A. M. Atributos morfológicos de seis variedades de cana-de-açúcar no pleno desenvolvimento vegetativo. Colloquium Agrariae, v.1, n.2, p.16-22, 2005.

Oliveira, R. A.; Daros, E.; Zambon, J. L. C.; Weber, H.; Ido, O. I.; Zuffellato-Ribas, K. C.; Koerler, H. S.; Silva, D. K. T. Crescimento e desenvolvimento de três cultivares de cana-de-açúcar, cana planta, no Estado do Paraná. Scientia Agrária, v.5. n.1-2, p.87-94, 2004.

Oliveira, R. A.; Daros, E.; Zambon, J. L. C.; Weber, H.; Ido, O. T.; Zufellato-Ribas, K. C.; Koehler, H. S.; Silva, D. K. T. Crescimento e desenvolvimento de três cultivares de cana-de-açúcar, em cana-planta, no estado do Paraná: Taxas de crescimento. Scientia Agrária, v.6, n.1-2, p.85-89, 2005.

Oliveira, R. A.; Daros, E.; Zambon, J. L. C.; Weber, H.; Ido, O.T.; Zufellato-Ribas, K. C.; Koehler, H. S.; Silva, D. K. T. Área foliar em três cultivares de cana-de-açúcar e sua correlação com a produção de biomassa. Pesquisa Agropecuária Tropical, v.37, n.2, p.71-76, 2007. 
Orlando Filho, J.; Haag, H. P.; Zambello Júnior, E. Absorção dos macronutrientes pela cana-de-açúcar (Saccharum spp.) var. CB41-76, em três grandes grupos de solos do estado de São Paulo. Plant Physiology and Biochemistry, v.2, p.3-127, 1980.

Robertson, M. J.; Wood, A. W.; Muchow, R. C. Growth of sugarcane under high input conditions in tropical Australia: I. radiation use, biomass accumulation and partitioning. Field Crops Research, v.48, p.11-25, 1996.

Silva, C. T. S.; Azevedo, H. M. de; Azevedo, C. A. V. de; Dantas Neto, J.; Carvalho, C. M.; Gomes Filho, R. R. Crescimento da cana-de-açúcar com e sem irrigação complementar sob diferentes níveis de adubação de cobertura nitrogenda e potássica. Revista Brasileira de Agricultura Irrigada, v.3, n1, p.3-12, 2009.
Silva, L. C. Análise de crescimento e acúmulo nutrientes de sete cultivares de cana-de-açúcar na Região de Coruripe. Maceió: UFAL, 2007. 127p. Dissertação Mestrado

Stone, P. J.; Sorensen, I. B.; Jamieson, P. D. Effect of soil temperature on phenology, canopy development, biomass and yield of maize in a cooltemperature climate. Field Crops Research, v.48, p.169-178, 1999.

Terauchi, T.; Matsuoka, M. Ideal characteristics for the early growth of sugarcane. Japan Journal of Crops Science, v.69, n.3, p.286-292, 2000.

Teruel, D. A.; Barbiere, V.; Ferraro Júnior, L. A. Sugarcane leaf area index modeling under different soil water condintios, Scientia Agrícola, v.54, p.93-44, 1997.

Wiedenfeld, B.; Enciso, J. Sugarcane responses to irrigation and nitrogen in semiarid south Texas. Agronomy Journal, v.100, n.3, p.665-671, 2008. 